\title{
Thermal analysis of steel and aluminium pistons for a HSDI diesel engine
}

\author{
Nick Papaioannou, Felix Leach, Martin Davy \\ Department of Engineering Science, University of Oxford, UK
}

SAE Technical Paper - Author's Accepted Manuscript

\begin{abstract}
Chromium-molybdenum alloy steel pistons, which have been used in commercial vehicle applications for some time, have more recently been proposed as a means of improving thermal efficiency in lightduty applications. This work reports a comparison of the effects of geometrically similar aluminium and steel pistons on the combustion characteristics and energy flows on a single cylinder high-speed direct injection diesel research engine tested at two speed / load conditions (1500 rpm / 6.9 bar nIMEP and $2000 \mathrm{rpm} / 25.8 \mathrm{bar}$ nIMEP) both with and without EGR. The results indicate that changing to an alloy steel piston can provide a significant benefit in brake thermal efficiency at part-load and a reduced (but nonnegligible) benefit at the high-load condition and also a reduction in fuel consumption. These benefits were attributed primarily to a reduction in friction losses. In terms of energy transfer, switching to the steel piston design was shown to reduce heat transfer to the coolant, consistent with lower friction work and reduced conduction through the ring pack, and increase the energy transfer to the oil. Piston blowby was also greatly reduced. Ignition delay times and overall combustion durations were reduced with the steel piston design, possibly indicative of higher piston surface temperatures.
\end{abstract}

\section{Introduction}

Upcoming $\mathrm{CO}_{2}$ emission limits - $95 \mathrm{~g} / \mathrm{km}$ in Europe by 2021 and $97 \mathrm{~g} / \mathrm{km}$ in America by 2025 [1] - have led automotive manufacturers to explore a wide variety of methods to increase thermal efficiency. Studies have shown that between 10 to $25 \%$ of the fuel energy released in-cylinder is transferred to the cylinder walls (depending on load conditions) - and then to the engine coolant and oil [2,3]. Reducing this heat transfer thus has great potential for delivering significant improvements in thermal efficiency.

Ceramic-based coatings, usually of yttria-stabilized zirconia (YSZ), have been explored as a means of insulating the combustion chamber surfaces. Applied on a heavy duty diesel engine piston, these coatings have been demonstrated to reduce the instantaneous piston heat flux [4]. However, the expected benefits on thermal efficiency were not seen likely due to a penalty in volumetric efficiency resulting from the higher cylinder surface temperatures throughout the cycle $[5,6]$.

In order to overcome this disadvantage, researchers have recently developed new coating materials using silica reinforced porous anodised aluminium (SiRPA) that allow the combustion chamber surfaces to follow the transient gas temperature during the cycle [710]. The low thermal conductivity and heat capacity of these socalled "Temperature Swing Coatings" allows for fast surface cooling during the exhaust and intake strokes, thus maintaining volumetric efficiency, while also providing high surface temperatures in the late compression and early expansion strokes, thus leading to lower heat transfer losses from the hot gases to the walls. Application of a SiRPA coating on the piston of a diesel engine resulted in an

Page 1 of 12 improvement of $2 \%$ in fuel consumption and $\sim 1.5 \%$ in indicated work along with a reduction in heat losses and an increase in exhaust enthalpy [10]. The effects of this new coating on indicated work, heat losses and exhaust enthalpy have been shown to be independent of EGR rate and injection timing [9].

An alternative approach to managing in-cylinder heat transfer, as opposed to the application of surface coatings, is to change the material of the piston itself. Alloy steel pistons have been widely used in heavy-duty applications since their first introduction in the early nineties [11], both as full steel or articulated steel-aluminium designs. Initially, the use of steel pistons in the heavy-duty sector was motivated by the need to provide high durability and strength in face of high peak cylinder pressures $[12,13]$. The higher stiffness of the alloy steel also allowed for the reduction of piston wall thickness.

Recently, steel pistons have found their way into light-duty diesel applications, and apart from their structural benefits over the aluminium pistons, researchers have reported improvements in both brake and indicated fuel efficiency $[14,15]$.

The improvements in net indicated specific fuel consumption (nISFC) reported in these two studies were attributed to:

1. Higher piston surface temperatures due to the lower thermal conductivity of steel compared to aluminium, and consequently reduced heat transfer to the oil and coolant

2. Higher compression ratio due to smaller topland volume of the particular piston design that was considered

3. The lower thermal expansion rate of steel, which then allowed for smaller clearances between the liner and piston thus reducing blowby.

In terms of brake specific fuel consumption (bsfc), the additional benefits observed for the particular steel piston design tested in refs. 20 and 21 were attributed to a reduction in frictional losses, due to:

1. A shorter piston skirt

2. A reduction of piston side forces due to increased conrod length

The above results highlight the potential benefits of alloy steel pistons. However, with the notable exception of the referenced works, the effects of moving from conventional aluminium piston designs to similar alloy steel pistons in light-duty diesel engines are not widely reported within the open literature. This study then seeks to expand the knowledge by reporting observations from an experimental comparison between similar aluminium and steel pistons on a single cylinder high-speed direct injection diesel research engine at two speed / load conditions (1500 rpm / 6.9 bar nIMEP and $2000 \mathrm{rpm} / 25.8$ bar nIMEP) both with and without EGR. 


\section{Experimental equipment and test procedure}

\section{Engine}

The engine used in this work is a single-cylinder direct injection diesel engine based on a Ricardo Hydra research engine. A split cooling system is employed enabling attribution of different cooling energy flows to the head and the cylinder liner. The engine configuration and its peripherals have been described in detail in a previous publication [16]. Table 1 provides a summary of key information.

Table 1: Engine specifications and fuel properties

\begin{tabular}{lc}
\hline Bore $\times$ Stroke & $83 \times 92.4 \mathrm{~mm}$ \\
Displacement & $500 \mathrm{~cm}^{3}$ \\
Valves per cylinder & 2 intake, 2 exhaust \\
Compression ratio & $15.4: 1$ \\
Fuel pressure & $400-2200 \mathrm{bar}$ \\
\hline
\end{tabular}

Figure 1 shows the geometries of the two piston designs. It can be seen that, although the alloy steel piston shares the same combustion bowl geometry (and compression ratio) as the baseline aluminium piston, there are notable differences between the designs that have been facilitated by the change to a stronger, more rigid material. The total length of the piston (L) has been reduced by $~ 23 \%$ and the top land (TL) by $\sim 55 \%$. Compression height is also reduced, necessitating an increase of approximately $5 \%$ in conrod length for the steel piston. Wall thicknesses have been reduced leading to a $\sim 50 \%$ increase in the cooling gallery volume. Note here that the ringpack design was the same for both pistons and that two piston cooling jets (PCJs) were used for the steel piston design as opposed to a single PCJ for the baseline aluminium piston. All other engine components remained constant across all tests.

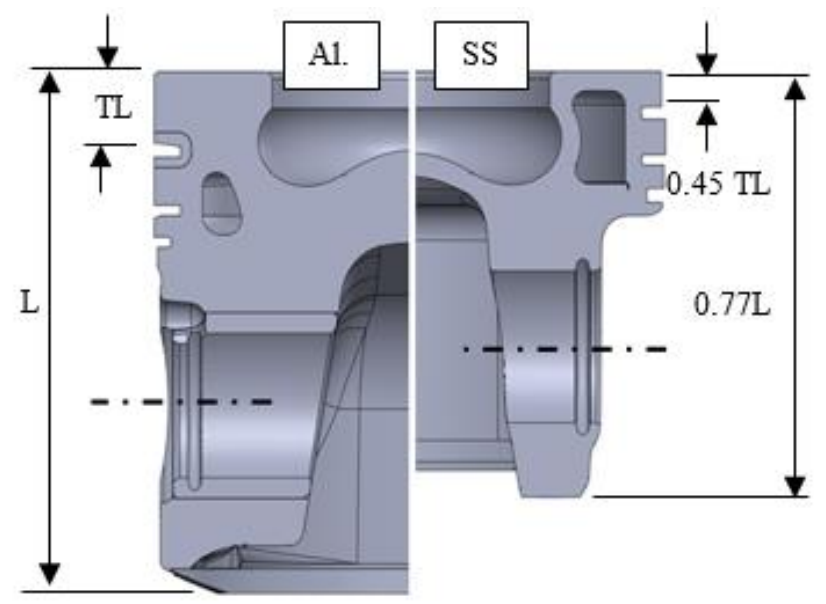

Figure 1: Comparison of aluminium (left) and alloy steel piston (right) designs (not to scale).

\section{Instrumentation}

The instrumentation used in this work has been presented in detail in previous studies [3]. Crank-angle resolved cylinder pressure data were measured using a piezoelectric Kistler transducer and logged with a high-speed data acquisition unit, AVL Indicom at a resolution of $0.1 \mathrm{CAD}$. Low frequency channels (at $1 \mathrm{~Hz}$ ) were logged using the CADET engine control system by Sierra-CP engineering. Highaccuracy differential thermocouples, employed in past studies [3], were used to measure the small coolant temperature differences observed across the engine. Blowby measurements were made with an Amber Instruments VF563 series flowmeter.

Fuel flow in the test facility is measured by a series combination of gravimetric and Coriolis measurement devices. Measurements from the individual devices are in agreement within $95 \%$ confidence intervals. The combined data set gives an estimated uncertainty of $\pm 0.0007 \mathrm{~g} / \mathrm{s}$ at the low load condition and $\pm 0.007 \mathrm{~g} / \mathrm{s}$ at the higher load. Engine out emissions are measured via a Horiba MEXA One analyzer. Air/fuel ratio, and hence air flow, is subsequently derived from the emissions data using specie equilibrium analysis [17]. The calculated air flow rate is cross-checked against direct measurements from a hot-wire anemometer. Again, the calculated and direct air flow measurements agree within $95 \%$ confidence limits. A simplified schematic of the instrumentation set-up can be seen in Figure 2.

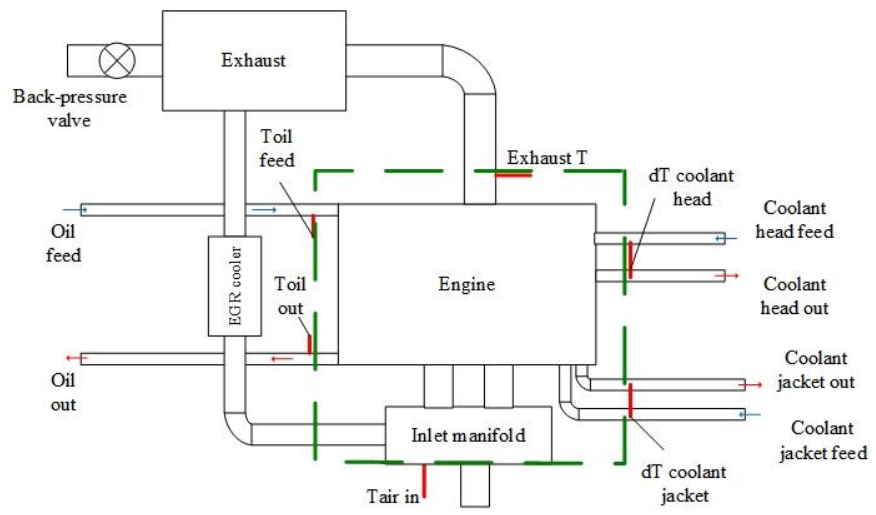

Figure 2: Engine instrumentation schematic. The green dotted line represents the control volume for the energy balance calculations.

\section{Test procedure}

The engine was operated at two different speed and load conditions in order to assess the performance of the two piston designs. The intake temperature was held constant at $40{ }^{\circ} \mathrm{C}$ and the coolant and oil inlet temperatures were controlled to $90{ }^{\circ} \mathrm{C}$. Two EGR set points were run at each engine speed, one at zero EGR and a second point with EGR (where the EGR rate varied according to the load condition). Table 2 presents the operating conditions for the two test cases. Combustion phasing was fixed by controlling the CA50 to a constant value via closed loop control on an electronic control unit (ECU). 
Table 2: Engine operating conditions

\begin{tabular}{lcc}
\hline Test point & $\mathbf{1}$ & $\mathbf{2}$ \\
\hline Engine speed (rpm) & 2000 & 1500 \\
nIMEP (bar) & 25.7 & 6.92 \\
CA50 $\left({ }^{\circ} \mathbf{C A}\right.$ aTDC) & 13.3 & 7.2 \\
$\mathbf{T}_{\text {intake }}\left({ }^{\circ} \mathbf{C}\right)$ & 40 & 40 \\
$\mathbf{T}_{\text {coolant }}\left({ }^{\circ} \mathbf{C}\right)$ & 90 & 90 \\
$\mathbf{T}_{\text {oil }}\left({ }^{\circ} \mathbf{C}\right)$ & 90 & 90 \\
EGR $(\%)(\mathbf{0}$, max $)$ & 0,8 & 0,32 \\
$\lambda$ & $1.5,1.4$ & $2.4,1.5$ \\
Inlet pressure (barG) & 2.2 & 0.46 \\
Exhaust pressure (barG) & 3.0 & 770 \\
Fuel pressure (bar) & 1530 & \\
\hline
\end{tabular}

The bulk gas temperature was calculated using the properties of pure, dry air with an empirically determined coefficient to account for the modified mixture properties due to the fuel present in the cylinder and a varying specific heat ratio $(\gamma)$ based on temperature [18].

Prior to the recording of data, the engine was allowed to reach thermal equilibrium, so as to ensure constant temperature gradients across the engine. Once this was achieved, the low frequency channels were logged for 3 minutes and the high-speed channels were logged for 300 cycles. Finally, every test point was repeated 10 times to allow for a sufficient sample size for statistical analysis. All error bars presented in this work indicate the $95 \%$ confidence intervals of the data.

\section{Energy Balance model}

Figure 3 details the control volume used for the first law analysis and the energy flows across the control volume boundary. The energy inputs to the control volume comprise; the fuel chemical energy, the enthalpy of intake air, the enthalpy of the EGR gases and the heat supplied by the oil sump heaters (note that results are presented as a fraction of this total input energy). The measured or calculated energy out terms from the control volume are: the energy to the oil, brake work, energy to the coolant, exhaust enthalpy, exhaust chemical energy and a term for extraneous losses, which lumps together all of the unaccounted energy terms. Note that, as discussed below, the effect of blowby gases on the overall energy balance calculations was expected to be negligible and that blowby is therefore not considered in the model.

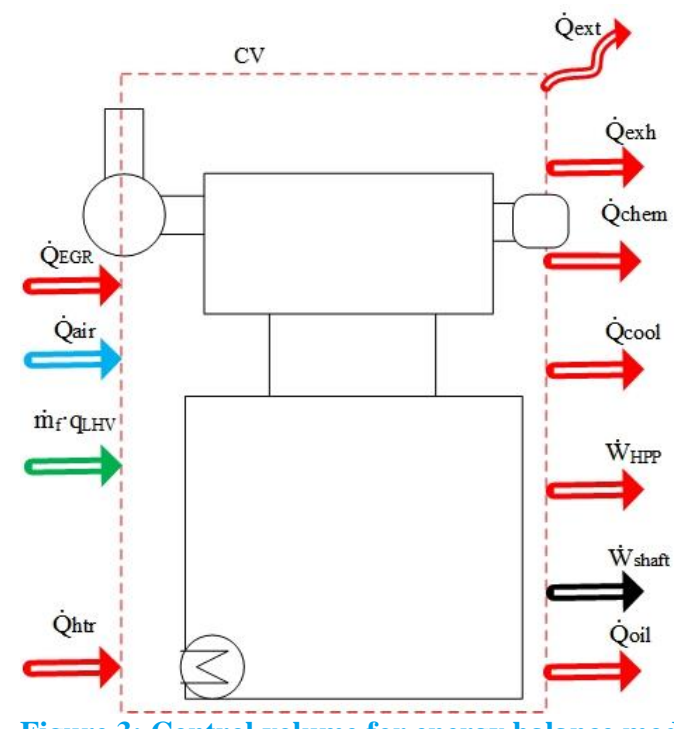

Figure 3: Control volume for energy balance model showing the input (left) and output (right) parameters (adapted from [3]).

The first law analysis model is described in detail in a previous study [3]. The chemical energy of the exhaust gases is calculated from the oxidation energy of $\mathrm{CO}, \mathrm{H}_{2}$ and total hydrocarbon (THC) species, with the THCs assuming to have the same composition as the input fuel. Thus, the chemical energy of unburned THCs was calculated from the calorific value of the fuel. The equilibrium equations for $\mathrm{CO}$ and $\mathrm{H}_{2}$ oxidation are shown below:

$$
\begin{aligned}
& \mathrm{CO}+0.5 \cdot \mathrm{O}_{2} \leftrightarrow \mathrm{CO}_{2} \\
& \mathrm{H}_{2}+0.5 \cdot \mathrm{O}_{2} \leftrightarrow \mathrm{H}_{2} \mathrm{O}
\end{aligned}
$$

Note that the chemical energy of the THCs is then an order of magnitude higher than that of the $\mathrm{CO}$ and $\mathrm{H}_{2}$ species. Considering the small proportion of exhaust chemical energy with respect to the total energy input $(\sim 0.3 \%)$, and the very low levels of CO measured in the exhaust, the contribution of $\mathrm{CO}$ and $\mathrm{H}_{2}$ oxidation in the total chemical energy of the exhaust gases is assumed negligible.

Published work carried out on diesel crankcase emissions [19, 20] indicates that approximately $0.3-4 \%$ of the total exhaust THCs find their way into the crankcase, due to blowby. Thus, even when the worst-case scenario of $4 \%$ is considered, this is a small percentage of an already very small value. Indeed, for the conditions tested here, the energy associated with blowby gases-both chemical (considering only unburned THCs) and thermal energy (from blowby measurements)- is estimated to be $0.01 \%$ and $0.03 \%$ of the total energy input respectively. Consequently, the effect of blowby on the accuracy of the first law analysis model is expected to be minimal.

\section{Results}

In this section the experimental results comparing the performance of the steel and aluminum pistons are presented. The results of the first law model are presented first and then further supported by analysis of heat release data. The effect of trapped mass on engine performance is also discussed. All fuel consumption and emissions results presented in this work have been rescaled by dividing by a nominal value - the same nominal value for all load points and chosen to ensure the maximum values of the data presented are close to 1 . 
2000 rpm / 25.7 bar- no EGR

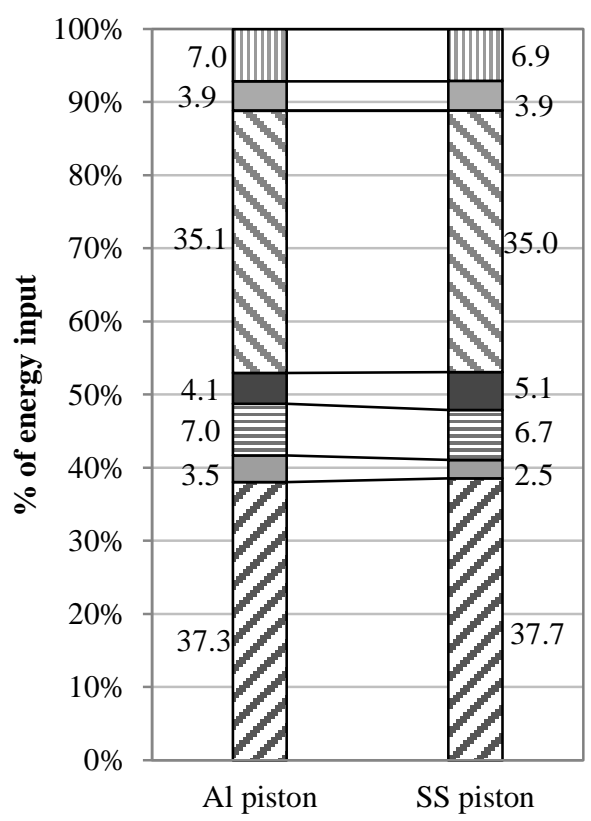

Figure 4: First law analysis results for aluminium and stainless steel pistons for the $2000 \mathrm{rpm} / 25.7$ bar nIMEP - no EGR case. Results presented as percentage of total energy input.

\section{0 rpm / 25.7 bar - 8\% EGR}

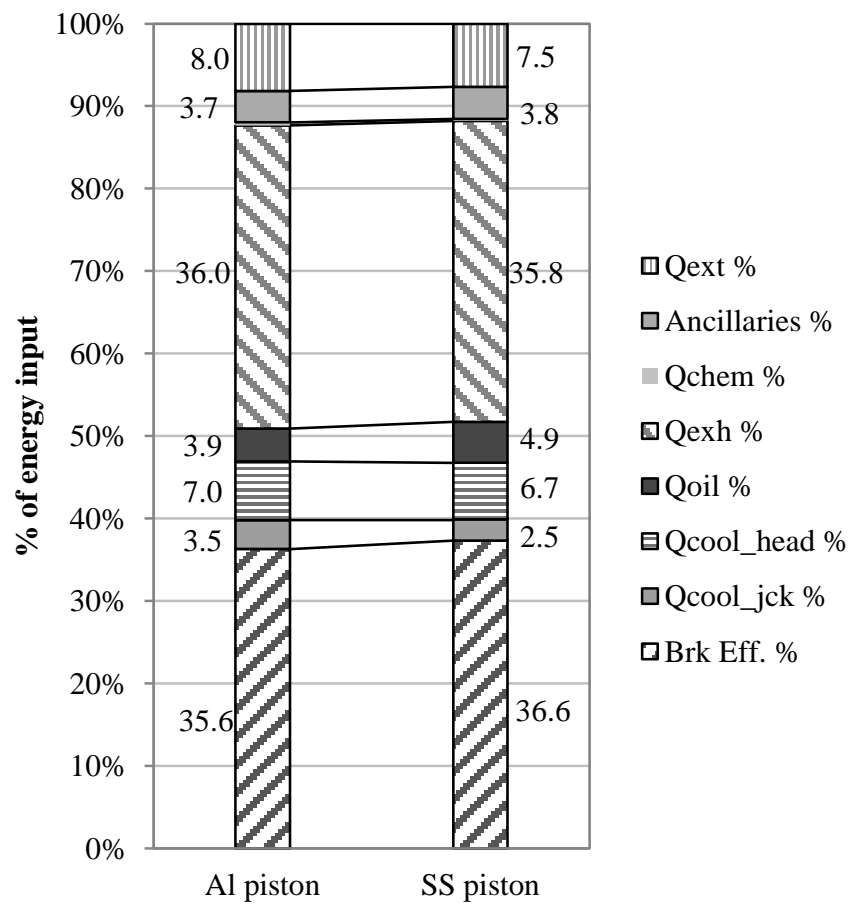

Figure 5: First law analysis results for aluminium and stainless steel pistons for the $2000 \mathrm{rpm} / 25.7$ bar nIMEP - 8\% EGR case. Results presented as percentage of total energy input.

Page 4 of 12

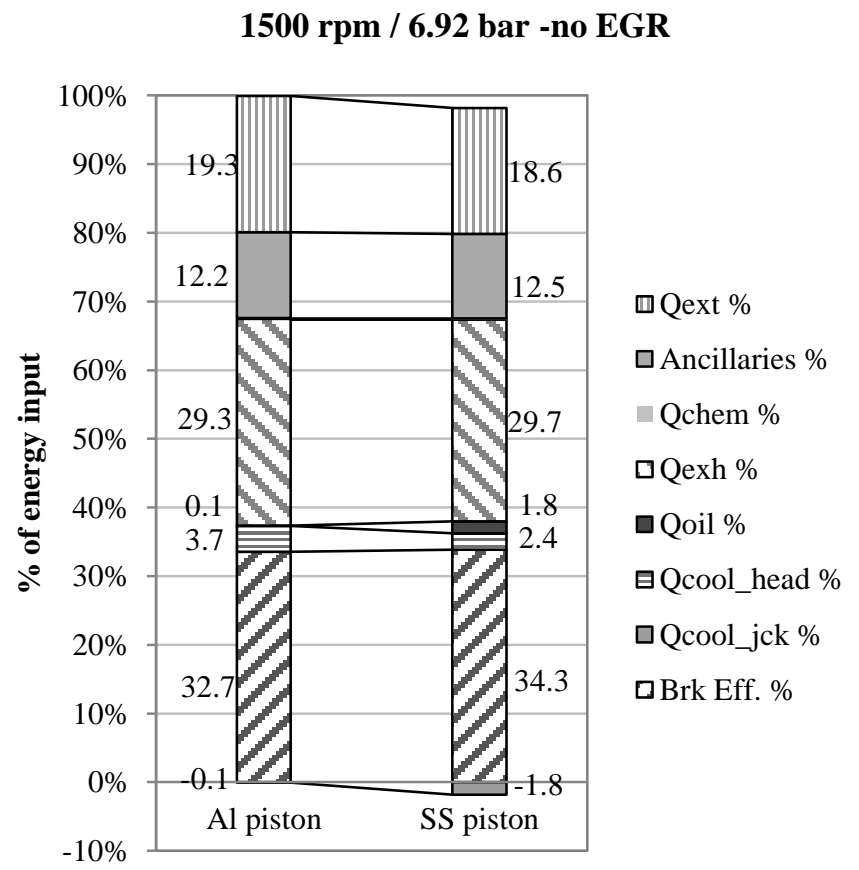

Figure 6: First law analysis results for aluminium and stainless steel pistons for the $1500 \mathrm{rpm} / 6.92 \mathrm{bar}$ nIMEP - no EGR case. Results presented as percentage of total energy input.

1500 rpm / 6.92 bar - 32\% EGR

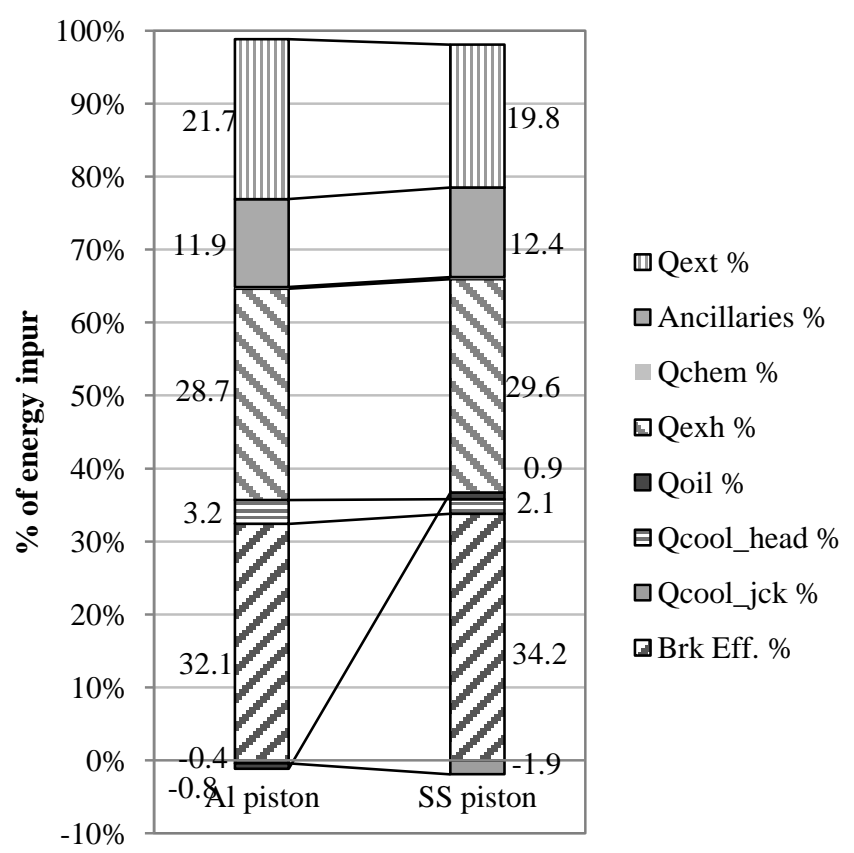

Figure 7: First law analysis results for aluminium and stainless steel pistons for the $1500 \mathrm{rpm}$ / 6.92 bar nIMEP - 32\% EGR case. Results presented as percentage of total energy input. 
Figures 4 to 7 show the results of the energy balance model for the conditions presented in Table 2 . All values are presented as percentage of the total energy input. The $95 \%$ confidence intervals are not included in the figures so as to aid clarity (these statistical results are tabulated in Appendix A for the interested reader).

The results show statistically significant increases in brake efficiency for all four test points when switching from the baseline aluminium piston to the steel piston design. The observed benefits are relatively small at high load (2000 rpm / 25.7 bar nIMEP, Figures 4 and 5). A benefit of $\sim 0.6 \%$ is observed for the $0 \%$ EGR condition and $\sim 1 \%$ with $8 \%$ EGR. The benefits are more pronounced for the low speed / load case (1500 rpm / 6.92 bar nIMEP, Figures 6 and 7) where improvements of $\sim 2.2$ and $\sim 1.6 \%$ are seen for the $0 \%$ and $32 \%$ EGR conditions respectively.

The results also show a consistent reduction in energy transfer to the coolant both in the jacket and the head with the steel piston. More specifically, the energy to the coolant in the jacket is reduced by 1 percentage point (which corresponds to an equivalent temperature drop across the engine of $0.8 \mathrm{~K}$ ) for the $2000 \mathrm{rpm} / 25.7$ bar nIMEP $0 \%$ EGR case. Similar magnitude reductions were noted with EGR. As the speed and load are reduced, the energy transfer to the cooling jacket is negative, indicating that the coolant is transferring energy to the cylinder walls (the inlet coolant temperature was controlled to the same set point). A higher negative value is seen for the steel piston design indicating a reduction in the energy transferred from the cylinder to the jacket coolant circuit compared with the aluminium piston.

The energy transferred to the coolant in the head is comparatively higher than the transfer to the jacket (by as much as $\sim 4$ percentage points) irrespective of piston design and operating condition. Here, steel piston operation resulted in a reduction of $\sim 0.3$ percentage points independent of EGR for the $2000 \mathrm{rpm} / 25.7$ bar nIMEP case, and a reduction of $\sim 1.2$ percentage points under the $1500 \mathrm{rpm} /$ 6.92 bar nIMEP condition.

The proportion of the input energy transferred to the oil circuit was increased by approximately 1 percentage point, across all test conditions, for the steel piston design.

With regards to the exhaust gas enthalpy, the observed changes between the aluminium and steel piston designs were within the $95 \%$ confidence limits and therefore not statistically significant. Similarly, no appreciable differences in ancillary or extraneous losses were observed between the aluminium and steel pistons designs under the same speed / load conditions with the exception of the $1500 \mathrm{rpm} /$ 6.92 bar EGR condition where a small increase is seen with the steel piston.

Figure 8 shows the experimental data for Friction Mean Effective Pressure (FMEP), where FMEP = IMEP - BMEP. It is shown that moving from the aluminium to the steel piston design resulted in a reduction in FMEP of the order of 6-10\% for all test conditions. It is also seen (as might be expected) that FMEP is independent of EGR rate.

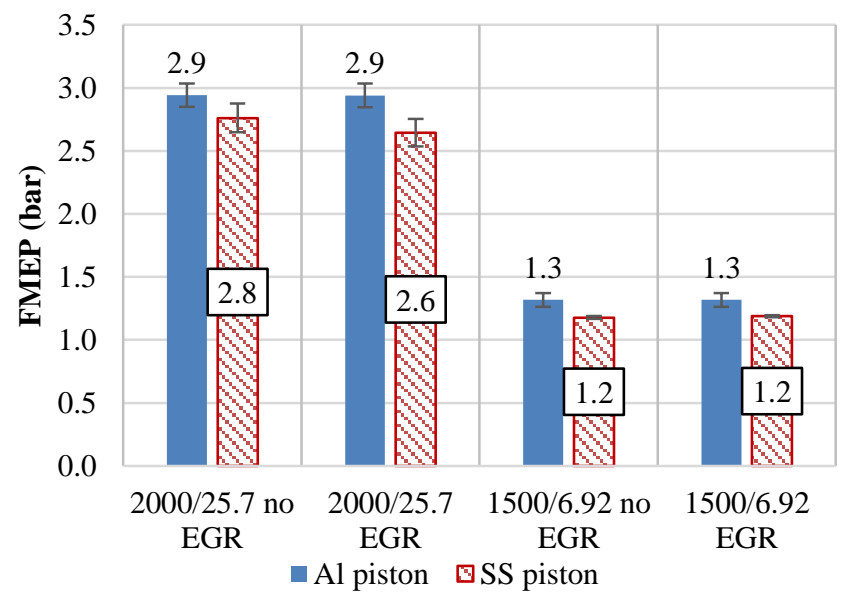

Figure 8: FMEP comparison for the conditions tested. The error bars indicate the $95 \%$ confidence limits.

Figures 9 and 10 show, respectively, the rescaled net indicated specific and the brake specific fuel consumption. In all cases, the fuel consumption was reduced for the steel piston design. The differences are uniformly statistically significant for BSFC, but are less clear-cut for nISFC where they are noted to be statistically insignificant for the higher speed / load case. BSFC was reduced by $\sim 1.2-2.5 \%$ for the higher speed / load condition, and $\sim 3.5 \%$ for the lower speed / load case. The reductions in nISFC were of the order $0.5 \%$ for the $2000 \mathrm{rpm} / 25.7$ bar nIMEP conditions and between 0.9 and $1.3 \%$ at the $1500 \mathrm{rpm} / 6.9$ bar nIMEP condition depending on EGR rate.

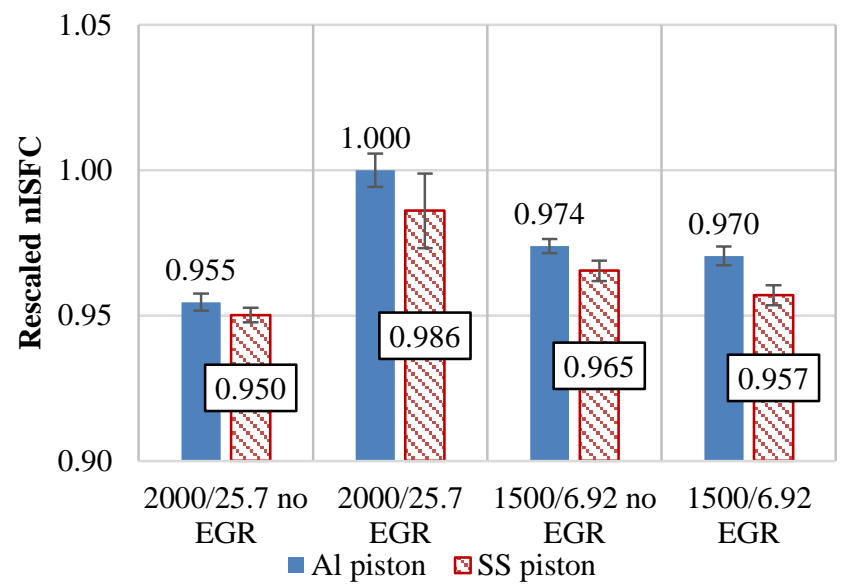

Figure 9: Rescaled nISFC comparison for the conditions tested. The error bars indicate the $95 \%$ confidence limits. 


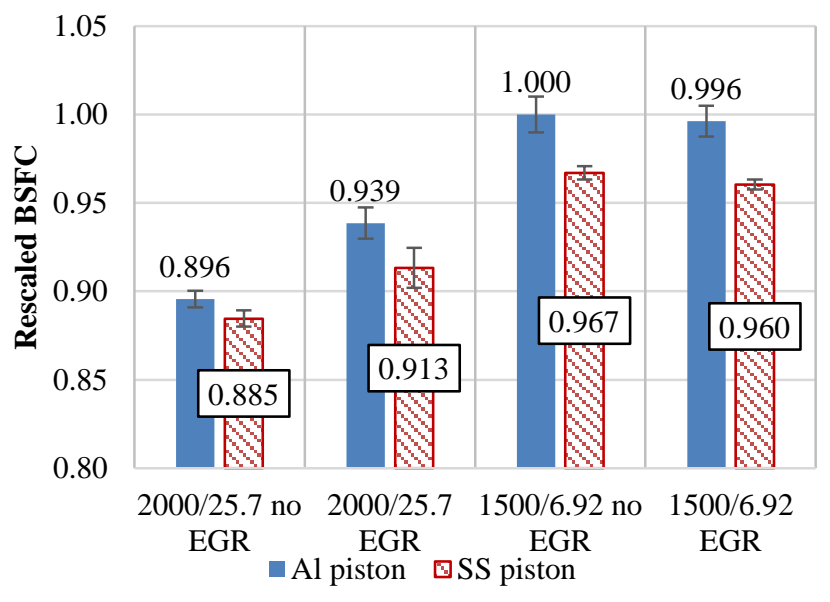

Figure 10: Rescaled BSFC comparison for the conditions tested. The error bars indicate the $95 \%$ confidence limits.

Figure 11 shows the measured time average mean exhaust temperatures for all conditions and pistons examined. It is seen that the use of the steel piston design results in consistent, small ( $\sim 1.3$ to $2.5 \%$ ), but statistically significant decreases in mean exhaust gas temperature. A note on the detail of these exhaust temperature measurements is included in [25].

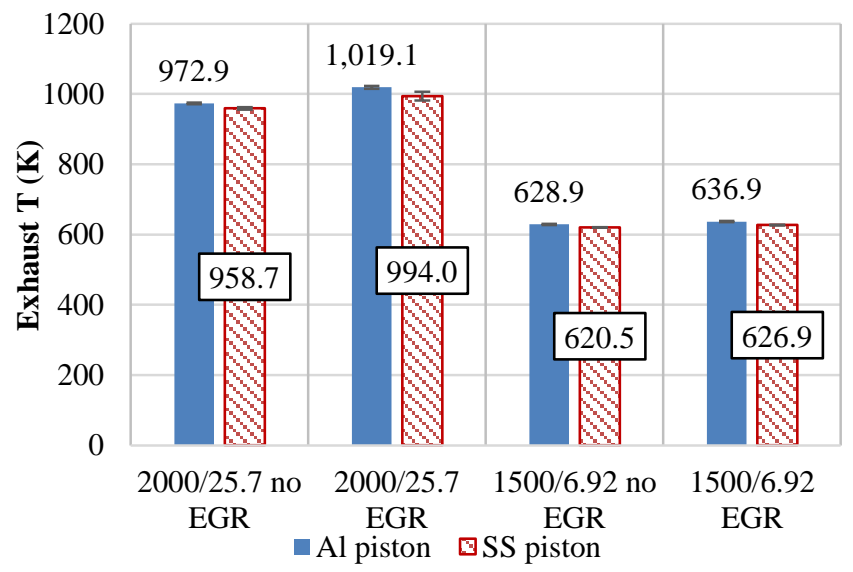

Figure 11: Mean time-averaged exhaust gas temperature for all conditions and pistons tested. The error bars indicate the $95 \%$ confidence limits of the data.

Figure 12 shows the ignition delay results, averaged over 3000 cycles, measured over 10 experimental runs each 300 cycles long. In this work, the ignition delay is defined as the interval between the start of the main injection (MSOI) and the point of $10 \%$ mass fraction burned (MFB) - a reminder that each test point was run with a fixed $50 \%$ MFB. The results show that ignition delay is reduced under steel piston operation, independent of engine load and EGR rate.

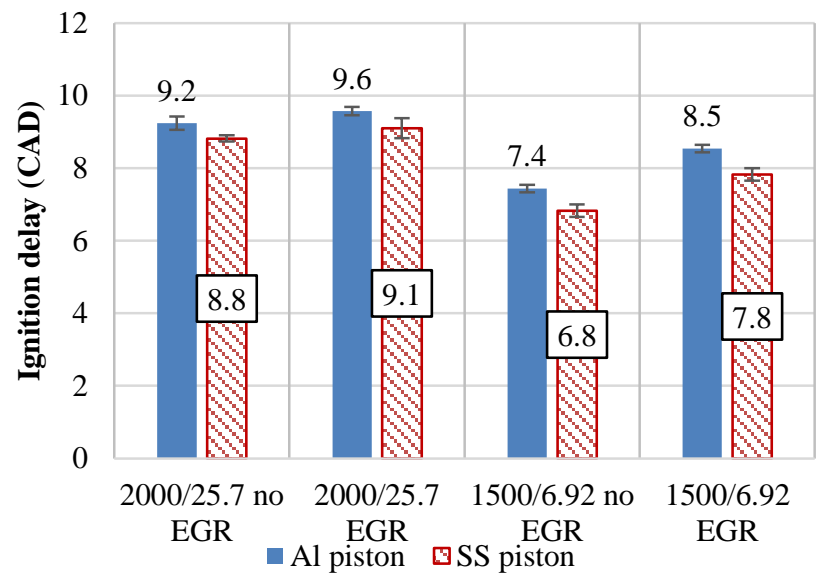

Figure 12: Ignition delay results for the conditions tested. Results are averaged over 10 experimental runs comprised of 300 cycles each. Ignition delay is defined as MSOI-MFB10\%.

Figures 13 and 14 show, representative cumulative heat release rate data, for the $2000 \mathrm{rpm} / 25.7 \mathrm{bar}$ nIMEP and the $1500 \mathrm{rpm} / 6.92 \mathrm{bar}$ nIMEP respectively. The dashed lines in these figures indicate the conditions of $0 \%$ EGR rate. Table 3 details the changes in ignition delay, early phase combustion duration (10 - 50\% MFB), late phase combustion duration (50 - 90\% MFB) and the overall combustion duration (10 - 90\% MFB) for the steel piston relative to the aluminium. Although the differences are small, there is a clear trend in that the use of steel piston results in a reduction of the ignition delay, a similar burn rate between 10 - 50\% MFB and a faster burn rate between 50 - 90\% MFB.

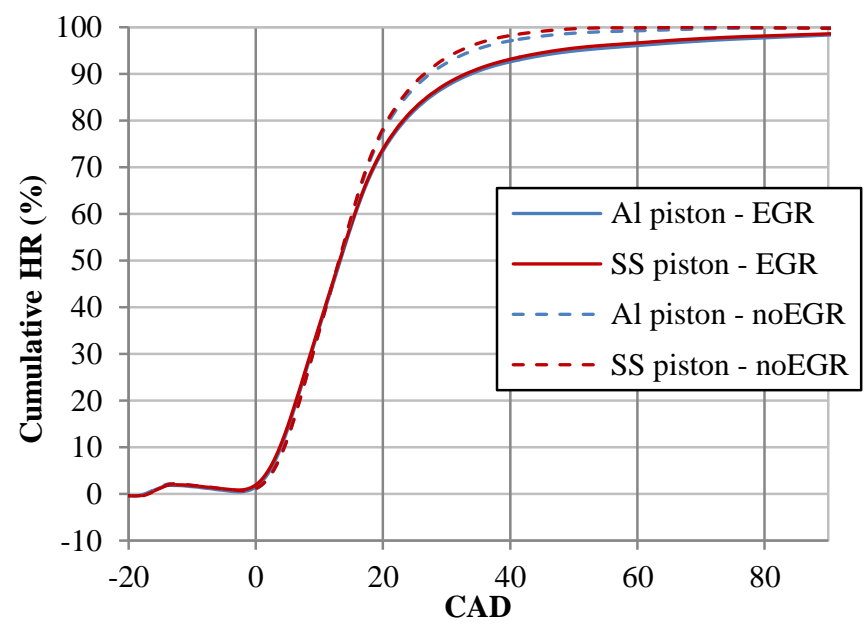

Figure 13: Representative cumulative heat release results for $2000 \mathrm{rpm} / 25.7$ bar nIMEP case. The dashed lines indicate the $0 \%$ EGR cases. 


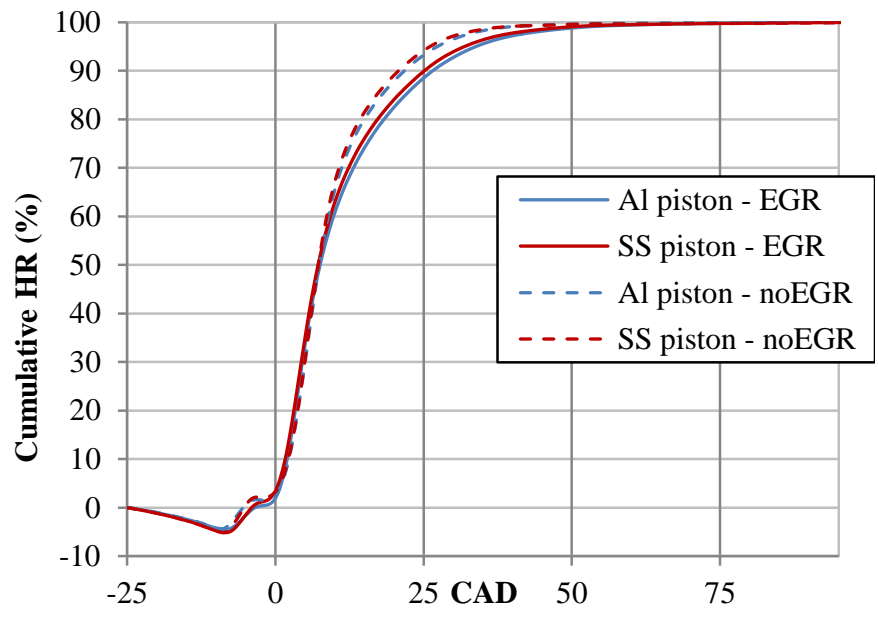

Figure 14: Representative cumulative heat release results for $1500 \mathrm{rpm} / 6.92$ bar nIMEP case. The dashed lines indicate the $0 \%$ EGR cases.

Table 3: Change in ignition delay and combustion duration values between aluminium and steel pistons. Negative values indicate reductions for the steel piston.

\begin{tabular}{lcccc}
\hline & $\begin{array}{c}\text { Ign. } \\
\text { Delay } \\
\text { (CAD) }\end{array}$ & $\begin{array}{c}\mathbf{1 0 - 5 0 \%} \\
\text { MFB } \\
\text { (CAD) }\end{array}$ & $\begin{array}{c}\mathbf{5 0 - 9 0 \%} \\
\text { MFB } \\
\text { (CAD) }\end{array}$ & $\begin{array}{c}\mathbf{1 0 - 9 0 \%} \\
\text { MFB } \\
\text { (CAD) }\end{array}$ \\
\hline $\mathbf{2 0 0 0 / 2 5 . 7}$ & -0.54 & 0.05 & -0.81 & -0.76 \\
$\mathbf{2 0 0 0} / \mathbf{2 5 . 7}$ EGR & -0.84 & 0.07 & -0.75 & -0.68 \\
$\mathbf{1 5 0 0} / \mathbf{6 . 9 2}$ & -0.32 & -0.07 & -0.84 & -0.91 \\
$\mathbf{1 5 0 0} / \mathbf{6 . 9 2}$ EGR & -0.65 & -0.01 & -1.08 & -1.09 \\
\hline
\end{tabular}

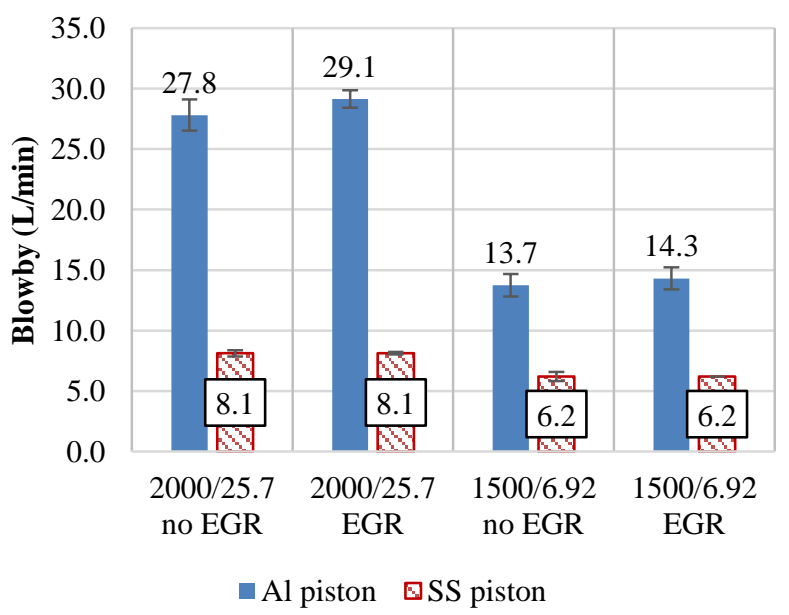

Figure 15: Blowby measurements for the conditions tested. The error bars indicate the $95 \%$ confidence limits.

Figure 15 presents the blowby measurements for the two pistons design under the four test conditions. Higher levels of blowby are seen for the higher speed / load conditions. Differences due to EGR rate are not statistically significant. The results show that blowby is significantly reduced with the steel piston design.

\section{Discussion}

Equation 3 details the relationship between brake work output, indicated work and the friction and ancillary losses of the engine.

$$
\text { brake } \text { work }=\text { ind. } \text { work }-(\text { friction }+ \text { ancillaries })
$$

Brake and indicated work are calculated in this work by using a load cell and the in-cylinder pressure trace respectively with their difference indicating the total losses due to friction and work required to drive ancillary components. In the current work, ancillary losses are restricted to the parasitic torque of the high pressure pump-this calculation is detailed in a previous study [3]. As described in this earlier work, the fuel pump is sourced from a production fourcylinder engine. Accordingly, the percentage of fuel pump work that is reported herein is noted to be much higher than would be expected on a production engine. Note also that these ancillary losses are constant at fixed injection pressure / speed / load conditions and that since nIMEP was held constant during testing in this work, any improvements that are observed in brake work between piston designs must relate directly to reductions in friction.

Heywood [21] reports that almost a third of the total energy to the coolant is due to friction between the piston and the liner. Thus, the reduced energy transfer to the coolant in the jacket - for all operating conditions and EGR rates - when operating with the steel piston is consistent with the reduced frictional losses associated with the design as shown in Figure 8. It is also consistent with the expected effects of the reduced skirt length and longer con-rod length associated with the steel piston, and in full agreement with the literature $[14,15]$. It should be recognized however that the energy transfer to coolant in the jacket is also affected by heat conduction through the piston ring pack and that the observed changes may not be due to frictional effects alone.

Mahle [22] state that, for a spray jet cooled aluminium piston, approximately $30 \%$ of the heat flow through the piston crown is dissipated through the ring pack (with approximately $50 \%$ going to the oil flow through the cooling galleries and the remaining $20 \%$ dissipated via the inner contour and the bottom part of the piston skirt). Thus, it is entirely possible that the observed reduction in energy transfer to the jacket coolant with the steel piston is the result of reduced conduction through the piston ring pack.

Exploring this thought further, there are clearly significant differences in the thermal properties of the two piston materials with the thermal conductivity of aluminium being approximately four times greater than that of steel. However, with reference to Figure 1, it is also clear that the effects of reduced thermal conductivity will be offset to some degree by the thinner wall thickness and greater cooling gallery surface area of the steel piston design - to the extent that a preliminary analysis indicates that the thermal resistance of the heat transfer path from the piston bowl and crown to the cooling galleries of the steel piston is similar or lower than for the aluminium piston.

The oil flow rate through the piston cooling galleries was neither controlled nor known in the present work, being governed by the oil supply to the engine and the flow resistance of the piston cooling circuit. As described previously, in addition to having an approximately $50 \%$ larger cooling gallery volume, the steel piston design utilises a twin PCJ arrangement compared to the single PCJ of the aluminium piston. These physical differences suggest that there should be less flow resistance for the steel piston cooling circuitand therefore a greater volume flow rate of cooling oil through the 
steel piston - for a fixed constant pump speed, and indeed an increase in the total flow rate of oil to the engine of $\sim 7 \%$ was measured for the steel piston design (Figure 16 refers).

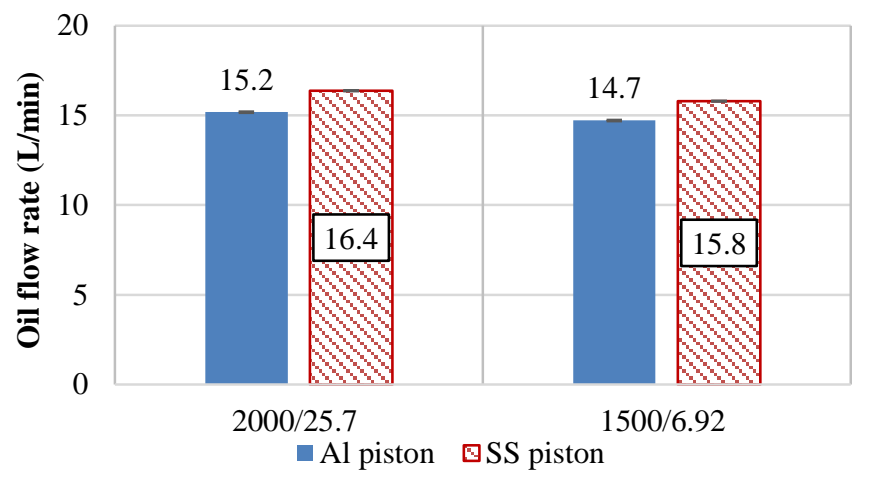

Figure 16: Total oil flow rate measurements for the conditions tested. The error bars indicate the $95 \%$ confidence limits.

An increase in oil gallery surface area and volume flow of rate oil would increase piston cooling, thereby reducing conduction from the ring pack to the coolant jacket, and increase the energy transfer to the cooling oil. Both of these trends are consistent with the experimental data. Note here that the increase in energy transferred to the oil with the steel piston (Figures 4 to 7 inclusive) observed in the current work is contrary to previously reported studies within the literature $[14,15]$. The authors attribute this apparent disagreement to differences in piston cooling arrangements between the current study and the referenced works. The previous studies employed an independent oil supply and conditioning system for piston cooling. As a result, the temperature and flow rate of the cooling oil to the piston could be varied independently from the lubricating oil to control piston temperature to set target values.

Whereas friction work and ring pack conduction are expected to influence the energy transfer to the coolant in the jacket directly, their influence on the coolant in the cylinder head is less clear. There is clearly some level of thermal contact between the liner and head. However, it is to be expected that this will be a minor effect and that dominant source of energy into the cylinder head coolant will be heat transfer from the combustion and exhaust gases. The reduced energy transfer to the cylinder head cooling circuit that is seen with the steel piston is then consistent with the reduction of exhaust gas temperature (EGT) that is noted for the steel piston design in Figure 11. This might also indicate that the change from the aluminium to steel piston has in some way caused a change in the combustion process.

The literature suggests that the lower thermal conductivity of steel will lead to higher piston surface temperatures [15], which would result in reduced heat flux between the hot combustion gases and the piston bowl and crown. Without direct measurement in the current work it is not possible to confirm or quantify changes in piston surface temperature; however the observations of reduced ignition delay in the present work (Figure 12) are consistent with the effects of increased piston surface temperature reported in the literature [23]. Similarly, the small increase in the mixing controlled burn rate reducing the overall combustion duration by $\sim 0.8-0.9^{\circ} \mathrm{CA}-$ that is presented in Figures 13 and 14, and Table 3 for the steel piston may also indicate a higher piston surface temperature as the increase in burn rate is consistent with the expected effects of reduced heat loss
[10]. In turn, the slightly earlier heat release could be responsible for minor reduction in exhaust gas temperature shown in Figure 11.

The reduction in blowby with the steel piston, as reported in Figure 15 , may also be significant with respect to the reduced ignition delay, piston temperature and in-cylinder heat transfer. As a fraction of the total intake mass, the measured blowby ranged from $\sim 1-3 \%$ independent of operating conditions, which is consistent with values reported in literature $[21,24]$. This would give approximately $1.3 \%$ more trapped mass for the steel piston than for the baseline aluminium case. A simple isentropic compression calculation, assuming a polytropic coefficient of 1.4 , indicates that an increase of $1.3 \%$ in trapped mass would give a corresponding increase in peak cylinder pressure of $\sim 1.4$ bar and indeed increases in peak cylinder pressure of this order were observed for the steel piston in the experimental results (Figure 17).

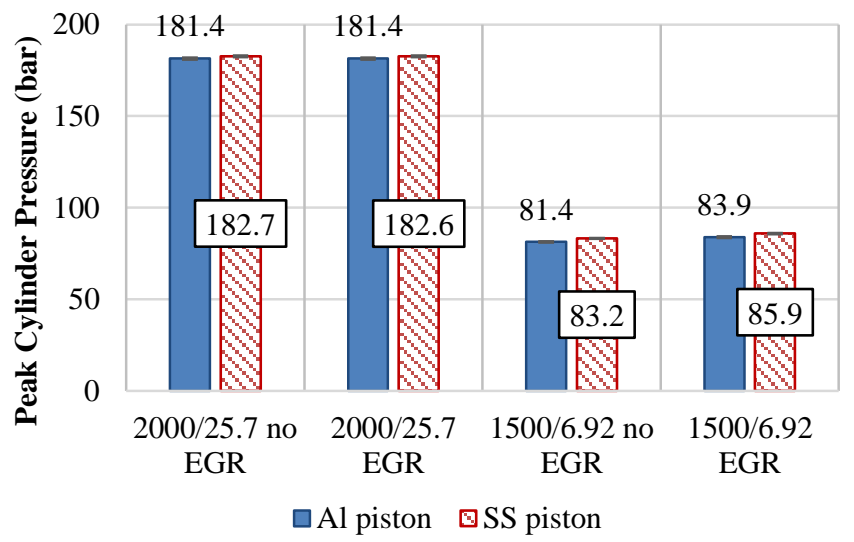

Figure 17: Peak cylinder pressure measurements for the conditions tested. The error bars indicate the $95 \%$ confidence limits.

The increased trapped mass and resultant higher in-cylinder pressures are expected to lead to higher bulk gas temperatures and higher indicated work for the steel piston design for a given energy input. However, the measured changes to the peak gas temperatures are small and although a constant trend of increasing temperature with the steel piston was seen the differences between the different piston materials were not statistically significant. Nevertheless, the improvements in nISFC shown in Figure 9 for the steel piston does indicate a positive effect on the indicated work, particularly at lower load, i.e. less fuel is required to achieve the target value of nIMEP. The results suggest that the indicated work for a given fuel input is increased by the combination of a small increase in trapped mass due to reduced blowby and a similarly small increase mixing-controlled burn rate. It can be seen in Figure 10 that the benefits of improved fuel usage combine with the reduction in frictional (and ancillary) losses shown in Figure 8 to yield substantial benefits in brake specific fuel consumption. However, as the friction, thermal, and parasitic characteristics of a single cylinder engine are significantly different to its multi-cylinder equivalent, the authors suggest that it is the indicated values that are of practical interest.

\section{Conclusions}

This study has compared the effects of different piston materials on the performance of a single-cylinder direct injection diesel engine. Two pistons design were tested, aluminium and steel, at two speed / 
load conditions and their performance was assessed using a first law analysis approach; all other engine parameters were held constant. This analysis was further supplemented by heat release analysis data. It was found that switching from the baseline aluminium piston to the steel piston design resulted in:

- A reduction of between 6 and $10 \%$ in frictional losses for all test conditions. This was attributed to the reduced total and topland heights of the steel piston design.

- A reduction of $\sim 1$ percentage point across all test conditions in the energy transferred to the jacket coolant. This reduction was attributed to the combination of reduced frictional losses and lower levels of heat conduction through the ring pack.

- A reduction of $\sim 1$ percentage point across all test conditions in the energy transferred to the cylinder head coolant circuit. The authors attribute this reduction to changes in the combustion characteristics as evidenced by the reduced ignition delay, faster mixing controlled burn rate and decreased exhaust gas temperature seen for the steel piston.

- Reduced piston blowby, consistent with the literature, which results in an increase in trapped mass of order $1 \%$.

- A reduction of between 0.5 and $1.3 \%$ in nISFC - where the larger increases were seen at the low speed / load conditiondue to the combination of an increase in trapped mass and the increased mixing-controlled burn rate.

- An increase of $\sim 1$ percentage point in the energy transferred to the oil as a result of the increased cooling gallery volume of the steel piston design and an increased volume flow of cooling oil associated with the steel piston design and its twin cooling jet configuration

- An increase in brake efficiency at all four conditions tested. The observed benefits are relatively small at high load. The benefits were more pronounced for the low speed / load case where improvements in the order of $2 \%$ were achieved.

Finally, the authors acknowledge the subtle and confounded nature of some of the observed results. Future work should include the measurement of piston surfaces temperatures or heat flux and the use of numerical simulations to help deconvolve the effects of blowby and faster burn rates on the combustion process and thus provide a better understanding on how a steel piston configuration affects engine performance and efficiency.

\section{References}

1. Johnson, T. and Joshi, A., Review of Vehicle Engine Efficiency and Emissions, SAE Technical Paper 2017-010907, 2017, https://doi.org/10.4271/2017-01-0907.

2. Smith, L., Preston, W., Dowd, G., Taylor, O. et al., Application of a First Law Heat Balance Method to a Turbocharged Automotive Diesel Engine, SAE Technical Paper 2009-01-2744, 2009, https://doi.org/10.4271/200901-2744.

3. Papaioannou, N., et al., Evaluation of exhaust gas recirculation techniques on a high-speed direct injection diesel engine using first law analysis. Proceedings of the Institution of Mechanical Engineers, Part D: Journal of Automobile Engineering. 0(0): p. 0954407017749110 , https://doi.org/10.1177/0954407017749110.

4. $\quad$ Binder, C., et al., Heat Loss Analysis of a Steel Piston and a YSZ Coated Piston in a Heavy-Duty Diesel Engine Using Phosphor Thermometry Measurements. SAE International Journal of Engines, 2017. 10(4): p. 1954-1968 https://doi.org/10.4271/2017-01-1046.
5. Dickey, D., The Effect of Insulated Combustion Chamber Surfaces on Direct-Injected Diesel Engine Performance, Emissions and Combustion, SAE Technical Paper 890292, 1989, https://doi.org/10.4271/890292.

6. Kimura, S., Matsui, Y., and Itoh, T., Effects of Combustion Chamber Insulation on the Heat Rejection and Thermal Efficiency of Diesel Engines, SAE Technical Paper 920543 , 1992, https://doi.org/10.4271/920543.

7. Kosaka, H., et al., Concept of "Temperature Swing Heat Insulation" in Combustion Chamber Walls, and Appropriate Thermo-Physical Properties for Heat Insulation Coat. SAE International Journal of Engines, 2013. 6(1): p. 142-149, https://doi.org/10.4271/2013-010274.

8. $\quad$ Fukui, K., Wakisaka, Y., Nishikawa, K., Hattori, Y. et al., Development of Instantaneous Temperature Measurement Technique for Combustion Chamber Surface and Verification of Temperature Swing Concept, SAE Technical Paper 2016-01-0675, 2016, https://doi.org/10.4271/2016-01-0675.

9. Wakisaka, Y., et al., Reduction of Heat Loss and Improvement of Thermal Efficiency by Application of “Temperature Swing” Insulation to Direct-Injection Diesel Engines. SAE International Journal of Engines, 2016. 9(3): p. 1449-1459, https://doi.org/10.4271/2016-01-0661.

10. Kawaguchi, A., Iguma, H., Yamashita, H., Takada, N. et al., Thermo-Swing Wall Insulation Technology; - A Novel Heat Loss Reduction Approach on Engine Combustion Chamber -, SAE Technical Paper 2016-01-2333, 2016, https://doi.org/10.4271/2016-01-2333.

11. Metoki, S. and Negishi, H., Why are NCI Pistons Not Used in Heavy Duty Diesel Engines?, SAE Technical Paper 2002-01-0164, 2002, https://doi.org/10.4271/2002-01$\underline{0164 .}$.

12. Kumarasekaran, K. and Safdari, Y., Thermal Stress Analysis of a Novel Design Air-Gap Insulated Piston, SAE Technical Paper 941069, 1994, https://doi.org/10.4271/941069.

13. Reipert, P., Mielke, S., and Essig, G., Pistons of DI-Diesel Engines with Reduced Heat Flow, SAE Technical Paper 891899, 1989, https://doi.org/10.4271/891899.

14. Schreer, K., et al., Analysis of Aluminum and Steel Pistons-Comparison of Friction, Piston Temperature, and Combustion. Journal of Engineering for Gas Turbines and Power, 2014. 136(10): 101506,

https://doi.org/10.1115/1.4027275/.

15. Gabriel, D. and Hettich, T., TopWeld $®$ Steel Piston for High Speed Diesel Engines, SAE Technical Paper 2015-011723, 2015, https://doi.org/10.4271/2015-01-1723.

16. Leach, F., Ismail, R., Davy, M., Weall, A. et al., Comparing the Effect of Fuel/Air Interactions in a Modern High-Speed Light-Duty Diesel Engine, SAE Technical Paper 2017-24-0075, 2017, https://doi.org/10.4271/201724-0075.

17. Stone, R., Introduction to Internal Combustion Engines. 4th ed. 2012, UK: Palgrave Macmillan.

18. AVL Concerto Application Notes. 2015.

19. Hare, C. and Baines, T., Characterization of Diesel Crankcase Emissions, SAE Technical Paper 770719, 1977, https://doi.org/10.4271/770719.

20. Clark, N., Tatli, E., Barnett, R., Wayne, W. et al., Characterization and Abatement of Diesel Crankcase Emissions, SAE Technical Paper 2006-01-3372, 2006 , https://doi.org/10.4271/2006-01-3372.

21. Heywood, J.B., Internal Combustion Engine Fundamentals. 1988: MacGraw-Hill 
22. Mahle, Pistons and engine testing. $2^{\text {nd }}$ ed. ATZ/MTZFachbuch. 2016: Springer Vieweg.

23. Ladommatos, N., Z. Xiao, and H. Zhao, The effect of piston bowl temperature on diesel exhaust emissions. Proceedings of the Institution of Mechanical Engineers, Part D: Journal of Automobile Engineering, 2005. 219(3): p. 371-388, https://doi.org/10.1243/095440705X6550.

24. Rao, V., Gardiner, D., and Bardon, M., Effects of Gas Leakage and Crevices on Cold Starting of Engines, SAE Technical Paper 940078, 1994,

https://doi.org/10.4271/940078.

25. Papaioannou, N., Leach, F., and Davy, M., Effect of Thermocouple Size on the Measurement of Exhaust Gas Temperature in Internal Combustion Engines, SAE Technical Paper 2018-01-1765, 2018, https://doi.org/10.4271/2018-01-1765.

\section{Contact Information}

Felix Leach

Department of Engineering Science, University of Oxford, Parks Rd, Oxford, OX1 3PJ, UK

Email: felix.leach@eng.ox.ac.uk

\section{Acknowledgments}

The authors would like to thank the Jaguar Land Rover Limited and University of Oxford John Fell fund for financial support. Nick Papaioannou would like to thank EPSRC for supporting his research (Grant number: 1515450). The authors would also like to thank BP International for supplying the Diesel. Adam Weall and David Richardson are acknowledged for technical support. Finally, the authors would like to thank Liyah Dholiwar for undertaking much of the engine testing and the Dept. of Engineering Science technicians and maintenance teams for facilities support.

\section{Definitions/Abbreviations}

BMEP

Brake Mean Effective Pressure

BSFC

Brake specific fuel consumption

CA50

ECU

Crank angle of $50 \%$ mass

fraction burned

Electronic control unit

Friction Mean Effective Pressure

Indicated Mean Effective Pressure

Mass fraction burned

MSOI

Main start of injection

NISFC

Net indicated fuel consumption

PSOI

Pilot start of injection

TDC

Top dead centre

THC

\section{Total hydrocarbons}

Lambda (relative air-fuel ratio)

Specific heat ratio 


\section{Appendix}

Table A1: Energy balance results for the $2000 \mathrm{rpm} / 25.7$ bar nIMEP 0\% EGR case (presented in Figure 4). Results include the 95\% confidence intervals.

2000 rpm / 25.7 bar nIMEP 0\% EGR

\begin{tabular}{lcc}
\hline & Al piston & SS piston \\
\hline Brk Eff. & $37.3 \pm 0.2$ & $37.7 \pm 0.2$ \\
Qcool_jck & $3.5 \pm 0.1$ & $2.5 \pm 0.1$ \\
Qcool_head & $7.0 \pm 0.1$ & $6.7 \pm 0.1$ \\
Qoil & $4.1 \pm 0.2$ & $5.1 \pm 0.2$ \\
Qexh & $35.1 \pm 0.1$ & $35.0 \pm 0.2$ \\
Qchem & $0.0 \pm 0.0$ & $0.0 \pm 0.0$ \\
Ancillaries & $3.9 \pm 0.0$ & $3.9 \pm 0.0$ \\
Qext & $7.0 \pm 0.3$ & $6.9 \pm 0.4$ \\
\hline
\end{tabular}

Table A2: Energy balance results for the $2000 \mathrm{rpm} / 25.7$ bar nIMEP EGR case (presented in Figure 5). Results include the $95 \%$ confidence intervals.

2000 rpm / 25.7 bar nIMEP EGR

Al piston

$35.6 \pm 0.3$

Brk Eff.

Qcool_jck

Qcool_head

Qoil

Qexh

Qchem

Ancillaries
$3.5 \pm 0.0$

$7.0 \pm 0.1$

$3.9 \pm 0.1$

$36.0 \pm 0.1$

$0.4 \pm 0.0$

$3.7 \pm 0.0$

$8.0 \pm 0.3$
SS piston

$36.6 \pm 0.4$

$2.5 \pm 0.0$

$6.7 \pm 0.1$

$4.9 \pm 0.2$

$35.8 \pm 0.3$

$0.3 \pm 0.1$

$3.8 \pm 0.0$

$7.5 \pm 0.4$ 
Table A3: Energy balance results for the 1500 rpm / 6.92 bar nIMEP 0\% EGR case (presented in Figure 6). Results include the 95\% confidence intervals.

$1500 \mathrm{rpm} / 6.92$ bar nIMEP 0\% EGR

\begin{tabular}{ll} 
Al piston & SS piston \\
\hline $32.7 \pm 0.4$ & $34.3 \pm 0.4$ \\
$-0.1 \pm 0.3$ & $-1.8 \pm 0.1$ \\
$3.7 \pm 0.2$ & $2.4 \pm 0.2$ \\
$0.1 \pm 0.4$ & $1.8 \pm 0.1$ \\
$29.3 \pm 0.5$ & $29.7 \pm 0.3$ \\
$0.1 \pm 0.0$ & $0.2 \pm 0.0$ \\
$12.2 \pm 0.2$ & $12.5 \pm 0.1$ \\
$19.3 \pm 1.2$ & $18.6 \pm 1.0$
\end{tabular}

Brk Eff.

Qcool_jck

Qcool_head

Qoil

Qexh

Qchem

Ancillaries

Qext

Table A4: Energy balance results for the 1500 rpm / 6.92 bar nIMEP EGR case (presented in Figure 7). Results include the 95\% confidence intervals.

1500 rpm / 6.92 bar nIMEP EGR

Brk Eff.

Qcool_jck

Qcool_head

Qoil

Qexh

Qchem

Ancillaries
Al piston

$32.1 \pm 0.4$

SS piston

$34.2 \pm 0.5$

$$
-0.4 \pm 0.3
$$

$-1.9 \pm 0.1$

$3.2 \pm 0.2$

$2.1 \pm 0.2$

$-0.8 \pm 0.3$

$0.9 \pm 0.2$

$28.7 \pm 0.3$

$29.6 \pm 0.4$

$0.2 \pm 0.0$

$0.3 \pm 0.0$

$11.9 \pm 0.2$

$12.4 \pm 0.2$

$21.7 \pm 0.7$

$19.8 \pm 1.2$ 